\title{
A gestão de design na perspectiva da produção de ativos intangíveis na agricultura familiar: um estudo multicaso em joinville e blumenau no estado de santa catarina
}

\author{
Merino, Giselle Schmidt ${ }^{a}$; Zacchi, Giancarlo Philippi ${ }^{b}$; Merino, Eugenio Andrés Díaz ${ }^{c}$ Alves, \\ Adriana Tomazi ${ }^{\text {d }}$ \& Benevenutti, Dione Nery Cavalcantid \\ ${ }^{a}$ Programa de Pós-graduação em Design - Universidade Estadual de Santa Catarina, Brasil - \\ gisellemerino@gmail.com \\ ${ }^{b}$ Programa de Pós-graduação em Design - Universidade Federal de Santa Catarina, Brasil - \\ giancarlo.zacchi@posgrad.ufsc.br \\ ${ }^{c}$ Programa de Pós-graduação em Design - Universidade Federal de Santa Catarina, Brasil \& Programa de Pós- \\ graduação em Engenharia de Produção - Brasil - eugenio.merino@ufsc.br \\ ${ }^{\mathrm{d}}$ EPAGRI - Empresa de Pesquisa Agropecuaria e Extensao Rural de Santa Catarina.
}

\begin{abstract}
Resumo
A agricultura familiar é responsável por percentual significativo do valor de produção agropecuária. Enquanto a agricultura patronal gera $R \$ 358,00$ por hectare, a agricultura familiar gera $R \$ 677,00$ sendo, sendo $89 \%$ mais produtiva e respondendo por $10 \%$ do PIB (BRASIL, 2016). Santa Catarina contribui na dinâmica produtiva com 168.544 unidades em 2.645.088 ha. A gestão de design preocupa-se com o desenvolvimento e a gestão de processos, produtos, pessoas e serviços como elemento chave para o posicionamento e e incremento estratégico das organizações e neste contexto pode se transformar na força principal de mudança, aperfeiçoando a identidade a imagem e a comunicação, entendidos também como ativos intangíveis. O uso de bases taxonômicas neste contexto, pode contribuir a partir da organização das informações em um sistema de navegação que facilita a identificação em todos os níveis da produção agrícola familiar, para elaboração e verificação da produção de ativos intangíveis. O objetivo deste artigo é desenvolver uma base taxonômica com a finalidade de identificar os ativos intangíveis com base na gestão de design.

No que toca a metodologia este artigo caracteriza-se como exploratório e qualitativo envolvendo um estudo multicasco em 26 empreendimentos rurais em Joinville e Blumenau em Santa Catarina. Para tanto construiu-se uma base taxonômica estruturada em classe, subclasse, gênero e renque como suporte para navegação, organização e reusabilidade da informação e os resultados mostram que a valorização da agricultura familiar, nos casos em tela, pela quantidade de práticas, processos, insumos e equipamentos necessários identificados e classificados transforma entradas em saidas de qualidade, e dentro desta diversidade, é possivel a valorização, identificação e proteção por meioda gestão de design.
\end{abstract}

Palavras Chaves: Gestão de design; Ativos intangíveis; Valorização. 


\begin{abstract}
Family farming is responsible for a significant percentage of the agricultural production value. While the employer agriculture generates $R \$ 358.00$ per hectare, family farming generates $R \$ 677.00$ being, 89\% more productive and accounting for $10 \%$ of GDP (BRAZIL, 2016). Santa Catarina contributes to the productive dynamic with 168,544 units are in 2,645,088 ha. The design management is concerned with the development and management processes, products, people and services as a key element for positioning and strategic development of organizations and in this context may become the main force for change, perfecting identity image and communication also understood as intangible assets. The use of taxonomic bases in this context, can contribute from the organization of information into a navigation system that facilitates identification at all levels of family farming, for the preparation and verification of production of intangible assets. The purpose of this article is to develop a taxonomic base for the purpose of identifying intangible assets based on design management. As regards the methodology this article is characterized as exploratory qualitative study involving a multihull in 26 rural enterprises at Joinville and Blumenau in Santa Catarina. Therefore built a structured taxonomic basis of class, subclass, gender and hedgerow as support for navigation, organization and reusability of information and the results show that the value of family farming, where screen, the amount of practices, processes, supplies and necessary equipment identified and classified transforms inputs into outputs quality, and within this diversity, recovery is possible, identification and protection through design management.
\end{abstract}

Keywords: Design management; intangible assets; Valuation.

\title{
1. Introdução
}

A valorização, a proteção e a identificação de pequenos grupos produtivos figuram como ativos intangíveis e como resposta das articulações da gestão de design na agricultura familiar (Merino et al, 2012; Teixeira, 2011; Neto, 2012).

A necessidade da produção agrícola familiar em atuar com produtos que viabilizem ao empreendimento rural, a permanência do homem no campo com dignidade sob a perspectiva de melhorar sua qualidade de vida continuamente e estimular o negócio sob a expectativa empresarial, proporciona a gestão de design um ambiente apropriado para a produção de ativos intangíveis que estimulam as cadeias produtivas da agricultura familiar.

A gestão de design alinhada com esta necessidade contribui para que esses ativos intangíveis estimulem o negócio, criando valores a partir de suas intervenções, tais como por exemplo na construção e gestão da marca, a partir da difusão dos benefícios funcionais e emocionais, na personalidade traduzida através do símbolo e da logotipia, bem como nas hiperconexões estabelecidas, conforme se vê na Figura 1. 


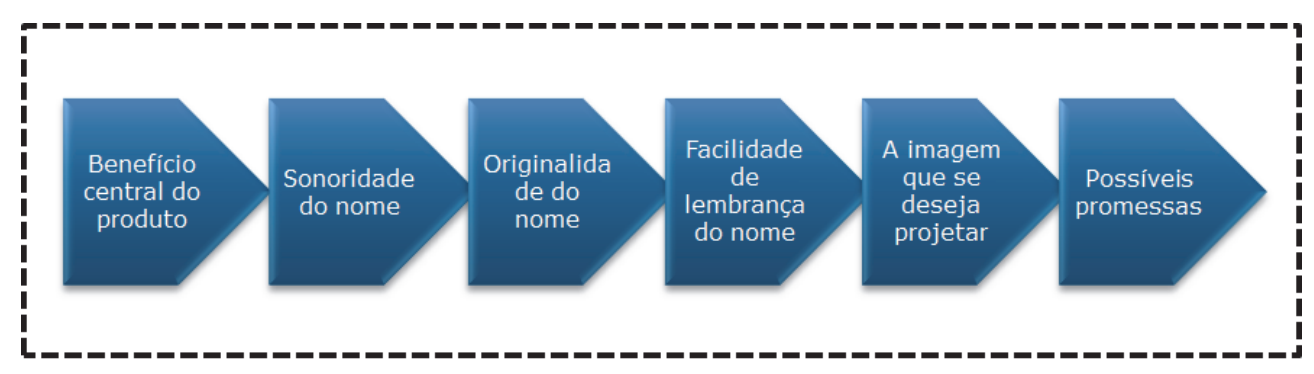

Fig. 1: Hiperconexões de valor. Fonte: $N G D / L D U$, (2016)

Em Santa Catarina as propriedades rurais demandam dessa assistência para interferir na capacidade produtiva para melhorar e proporcionar por meio desses ativos uma cadeia produtiva competitiva.

Os empreendimentos rurais devem administrar as incertezas proporcionadas por uma série de variantes, entre as quais destaca-se políticas públicas, transposição de fronteiras e gestão da informação, e que, ainda precisam ser eficazes no contexto do ambiente interno.

A gestão de design diminui essas incertezas, contribuindo para valorização de grupos produtivos por meio da identificação e proteção e da prática projetual, criando características que conferem unicidade aos produtos e serviços incrementando os ativos intangíveis.

Por isso o objetivo desse artigo é desenvolver uma base taxonômica com a finalidade de identificar os ativos intangíveis com base na gestão de design.

\section{Metodologia}

Com relação aos aspectos metodológicos este artigo se caracteriza como exploratório e qualitativo (Lakatos e Marconi, 2003). A pesquisa envolveu um estudo multicasco e para Gil (2002, p. 139), esta condição de múltiplos casos deixa a pesquisa mais robusta e "proporciona evidências inseridas em diferentes contextos, concorrendo para a elaboração de uma pesquisa de melhor qualidade".

O recorte espacial contempla, no Estado de Santa Catarina, as regiões de Joinville e Blumenau (Figura 2), compreendendo um universo de 26 empreendimentos rurais e pesqueiros. $\mathrm{O}$ projeto ja esta em desenvolvimento há dois anos. 


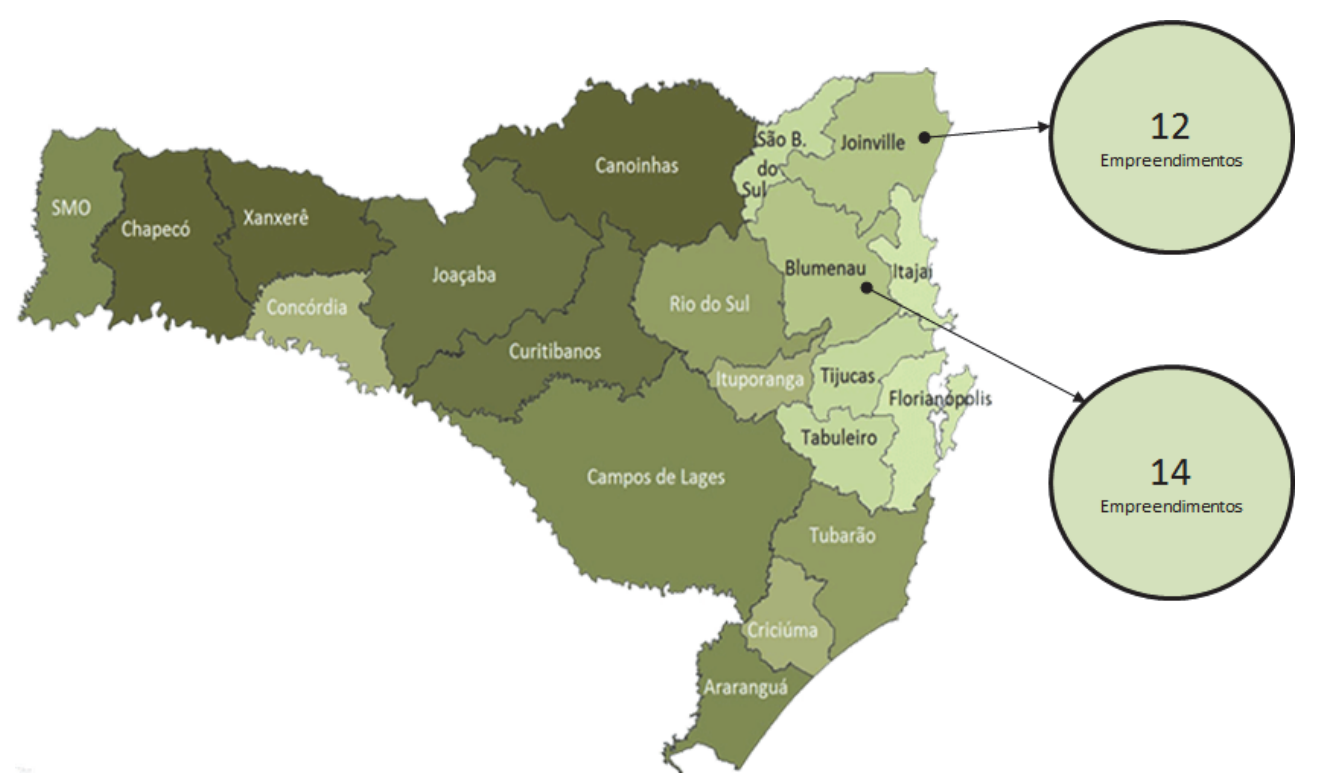

Fig. 2: Santa Catarina e as cidades de Blumenau e Joinville. Fonte: Epagri/Cepa (2016).

Quanto aos procedimentos metodológicos, após o delineamento da área espacial da pesquisa, definiu-se como problema a ser investigado, de que forma uma base taxonômica pode contribuir para a verificação da valorização, indentificação e proteção em pequenos grupos produtivos?

Para responder esta pergunta, procedeu-se a uma revisão da literatura em fontes primárias e secundárias. Após o levantamento bibliográfico, planejou-se as visitas, utilizando-se in locu, outras ferramentas como formulários e periféricos eletrônicos para coleta e registro dos dados e informações, sendo visitadas cada um dos 26 empreendimentos nesses dois primeiros anos de ações do projeto.

De posse das informações, procedeu-se ao tratamento e organização do volume de dados levantados. A fim de sistematizar as informações sem o risco de perder fatos e acontecimentos importantes, decidiu-se montar uma base taxonômica.

Para a montagem da base, utilizou-se o princípio da sequência canônica (Campos e Gomes, 2007), pois há uma ordem natural do conjunto de assuntos. Cada classe deu origem a uma subclasse de sustentação modalizada, quaternária, alfa numérica e policromática, explícita e consistente, que oferece ao leitor a possibilidade, pelo pensamento associativo, identificar o grupo, a cultura, a atividade e a perspectiva turística. A Figura 3, apresenta sinteticamente a estrutura. 


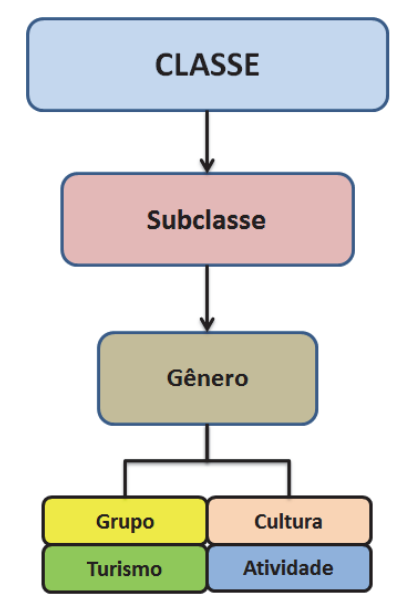

Fig. 3: Estrutura da base taxonômica. Fonte: NGD/LDU (2016).

A estrutura tipológica dos ambientes de domínio da presente base é constituída por três níveis e dois renques. O primeiro domínio chamado de classe reúne a temática de maior abrangência. É constituído pelos arranjos produtivos da fruticultura, olericultura, aquicultura e pesca, pecuária, gestão, floricultura e avicultura. A identificação dos conceitos ocorre no campo a partir do sistema produtivo da propriedade.

No segundo domínio da base, ou seja, a subclasse, 33 possibilidades de ocorrência se materializam, divididas em 15 variações na classe fruticultura, 4 na olericultura, 3 na aquicultura e pesca, 6 na pecuária, 1 na classe gestão, 2 na floricultura e finalmente 2 na classe avicultura. A modo de exemplo, as 2 possibilidades de ocorrência na classe avicultura, são nomeadamente: avicultura de corte e avicultura para produção de ovos.

O último domínio, cognominado de gênero, é estruturado em dois renques alinhados e dispostos na mesma fila e denominados de grupo e cultura; atividade e turismo (Figura 4).

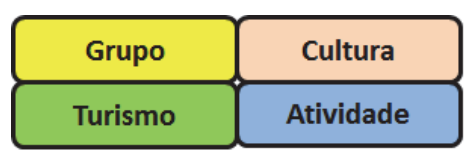

Fig. 4: Dois renques. Fonte: NGD/LDU (2016).

Compõe o microambiente nomeado de grupo (quadrículo amarelo), 8 maneiras produtivas que variam da comercialização de produtos in natura, a prestação de serviços de hospedagem, registrados a partir de uma sequência numérica. $\mathrm{O}$ segundo microambiente do primeiro renque, chamado cultura (quadrículo alaranjado), indica se o tratamento econômico e climato-ambiental é permanente ou sazonal, apresentando duas perspectivas registradas com letras maiúsculas.

O terceiro microambiente qualificado de atividade (quadrículo azul), assinala qual o status que é dado a atividade econômica e agrícola. Pode ser enquadrada como uma atividade principal ou secundária. A atividade será principal quando ela for a responsável pela produção do maior número de riquezas para a propriedade. É secundária quando for encarada como uma ação adicional e que incrementa o volume de riquezas produzidas. É representada de forma numérica. Finalmente o microambiente do segundo renque 
estabelecido como turismo (quadrículo verde), especifica se a propriedade tem intenção ou não de desenvolver a atividade turística no espaço rural, a partir de roteiros e circuitos turísticos organizados.

A base foi estrutura em uma planilha do Microsoft Excel (Figura 6) e sua leitura é horizontalizada e sempre partindo da esquerda para direita.

\section{A agricultura familiar e a gestão de design}

O processo de mudança socioeconômica e o aumento desordenado das cidades tem exigido cada vez mais a produção de alimentos em larga escala para suprir as necessidades humanas.

Neste panorama os agricultores familiares buscam maneiras de se adaptar a esta realidade, oferecendo a própria cidade sua produção rural. Este espaço de oportunidades por um lado proporciona formas de ampliar os negócios, mas por outro lado as carências que via de regra permeiam os pequenos produtores, transforma uma potencial oportunidade em uma fragilidade.

A reprodução das relações sociais no espaço rural, todavia, tem se mostrado até agora insuficientes para manter o agricultor familiar no campo, visto que as técnicas de produção, controle, embalagem e comercialização comprometem o negócio.

Portanto como atividade criativa e eminentemente integradora, a gestão de design pode conduzir os agentes envolvidos para o atingimento de seus objetivos auxiliando de forma racional o atingimento dos resultados pretendidos ampliando sua capacidade de inovação. Corroboram com este fundamento (Gorb, 1990) e (Goulart, Merino e Merino, 2013).

Muito embora a agricultura familiar seja importante para a produção alimentar, as políticas públicas e o desenvolvimento de tecnologias e processos produtivos privilegiam somente a agroindústria patronal, desconsiderando a relevância do meio rural na manutenção das sociedades.

Portanto o reconhecimento da agricultura familiar como força econômica fundamental (Brasil, 2010) desenvolve um conjunto de oportunidades em que a gestão de design acelera e melhora a qualidade de vida e as relações sociais dos envolvidos, aqueles que têm mais de $80 \%$ da sua renda advinda da atividade tradicional e cuja base de trabalho está nos membros da família (Bittencourt, Bianchini, 1996).

Por consequência a compreensão da gestão de design como mecanismo agregador de valor para a pequena propriedade enseja ações que levem esses pequenos negócios, a desenvolver uma série de mecanismos que oportunizem uma alavancagem, sobretudo aos processos produtivos, a fim de melhorarem seu desempenho global e valorizar seus ativos intangíveis.

\section{Os ativos intangíveis e a valorização da agricultura familiar por meio da identificação e proteção de pequenos grupos produtivos.}

A agricultura familiar antes chamada de subsistência sempre apresentou papel importante nas questões econômicas estando presente na rotina das atividades produtivas do Brasil (Mattei, 2014).

Como atividade representativa, apresenta 4,3 milhões de estabelecimentos agropecuários de natureza familiar. Representa $84 \%$ do total de módulos agrícolas do território. São mais de 12 milhões de pessoas ocupando $24 \%$ do território e respondendo por $38 \%$ da renda bruta.

Assim, enquanto a agricultura patronal gera $\mathrm{R} \$ 358,00$ por hectare, a agricultura familiar gera $\mathrm{R} \$ 677,00$ sendo, $89 \%$ mais produtiva respondendo por $10 \%$ do PIB (Brasil, 2016). Santa Catarina contribui na 
dinâmica produtiva dessas cadeias de produção, com 168.544 unidades em 2.645 .088 ha. O estado possui $90,5 \%$ desses estabelecimentos que ocupam $87 \%$ da área agrícola respondendo a $71,3 \%$ do valor bruto da produção, gerando mais de 240 mil empregos, $17 \%$ da força de trabalho.

A valorização da agricultura familiar por meio do design ocorre pela identificação e proteção desses pequenos negócios. A gestão de design se mostra catalizadora na criação de novos produtos, no incremento de produtos atuais e no desenvolvimento de identidade visual e proteção de marca através da propriedade e da indicação geográfica, e assim se transforma, para Castelão e Landim (2009), em uma ferramenta estratégica.

Diante do exposto cabe ressaltar que a identificação e proteção, proporciona aos pequenos grupos produtivos a perspectiva de se tornarem diferenciados e a competência para identificação e proteção de pequenos produtores é do Instituto Nacional de Propriedade Industrial.

A lei de propriedade industrial 9.279/96, regulamenta este dispositivo estratégico no âmbito do território brasileiro, que via de regra, atribui valor aos produtos através de sua vinculação territorial local, de acordo com o artigo 170 da supracitada lei.

O modelo avalia solo, condições climáticas, processo de produção, determinando territorialidades específicas, mas as principais questões para obtenção do título ainda são atribuídas ao conceito de coletividade, através dos fundamentos do associativismo e do território, o que implica na valorização bilateral dos dois fundamentos.

Essa mobilização associativa aliada às questões edafo-climáticas de dado território permitem a prospecção deste direito da propriedade industrial, e vem se tornando um dispositivo popular.

Niederle (2011. p. 18), defende que as indicações geográficas ensejam uma "revalorização de tradições, costumes, saberes, práticas e outros bens imateriais associados a uma identidade territorial e origem geográfica específica”.

Muito embora, não tenha se utilizado, no presente projeto, a indicação geográfica estabelece uma ligação entre o produto e a localidade geográfica de produção e ou de origem, o que para Neto (2011), cria um fator diferenciador dos produtos similares disponíveis no mercado e isso "possibilita a construção contínua de uma teoria mais ampla, mais competente e mais comprometida com as variáveis de interesse social" (Portuguez, 2001, p. 60).

A indicação geográfica divide-se em indicação de procedência e denominação de origem. Ambas concedem reputação ao produto pela origem geográfica ou que tenha se tornado conhecido como produtor de determinado produto e ou serviço. No entanto, destaca-se que até o presente momento, não se desenvolveu ações de indicação geográfica no projeto, relatado neste estudo.

A generosidade da terra e a ingratidão do homem, que sempre agiu no sentido de destruir, aniquilar, consumir e enfraquecer as produções e a substância da natureza (Pádua, 2002), tem exatamente na indicação geográfica, o seu oposto, pois requer a boa prática e uma excelente qualidade ambiental dos atributos geográficos.

A indicação geográfica possibilita ao consumidor, a certeza da origem geográfica do produto com suas características finais decorrentes dessa origem, e para o produtor a garantia de longevidade comercial. Essa diferenciação aumenta o valor agregado do produto e ou do serviço, preserva suas particularidades e estimula investimentos na área delimitada pela IG, valorizando a condição humana e as características do campo pela agricultura familiar. 
Figurando finalmente como mecanismo legal de identificação e proteção, ainda existe a marca coletiva que identifica produtos e serviços de uma determinada organização e a marca de certificação que oferece a evidência de uma certificação a partir de normas e especificações técnicas, caso das International Organization for Standardization - ISOs.

Estes mecanismos legais garantem a autenticidade dos processos produtivos e da identidade visual dos produtos, processos e serviços, cria um fator diferenciador e agrega valor, transformando-se nos ativos mais importantes do negócio (Neto, Teixeira e Merino, 2010).

Por estas razões Preto, Merino e Figueiredo (2011) afirmam que a planta deve incorporar a gestão de design na concepção estratégica do negócio, no design do produto e na análise de seu ciclo de vida. Como resultante desse processo os ativos intangíveis são destacados como uma contra resposta da incorporação de valor do agroecossistema.

Assim, por meio da gestão de design, todos os componentes que não são perceptíveis ao toque, ou seja, que não são corpóreos entre os quais chama-se atenção para a valorização a identificação e a proteção, passam a incorporar um ativo de capital que incrementa benefícios ao negócio e aos sujeitos diretamente ligados ao sistema.

Uma vez que está em curso no mercado a transição da valorização dos ativos tangíveis para uma supervalorização dos ativos intangíveis, entendidos como "bens e direitos colocados à disposição da empresa, que não tem existência física, mas que são capazes de gerar benefícios futuros para a entidade" (Garcia, 2001, p. 6) fica claro que a natureza física não é mais uma variante absoluta. Pelo contrário, os ativos intangíveis estimulam a percepção de perenidade que o mercado alvo passa a construir do negócio, da marca, das estratégias, do modelo de gestão consignado através de uma eficiente governança corporativa, mediada pelo design.

Ora, portanto a principal questão da valorização dos ativos intangíveis reside não em valores absolutos, mas na construção de uma curva de valor que seja e possa ser monitorada sistematicamente, uma vez a dificuldade em valorar contabilmente em modo de balança os valores desses ativos incorpóreos. Portanto, o resultado financeiro efetivo e final daquilo que é palpável está ligado diretamente como a consequência potencializadora do aumento da curva de valor avaliada sistematicamente através de uma matriz de avaliação de valor definida por atributos que sejam consistentes e comparativamente mais fortes que os concorrentes, causada pelos ativos intangíveis.

Dessa forma, estes ativos intangíveis, entendidos como tudo que não é corpóreo, tais como a preocupação com a sustentabilidade, a boa engenharia e os benefícios do produto e ou serviço, entre outros, evidenciados por intermédio da gestão de design, oferecem melhores condições de competitividade.

\section{Resultados e discussão}

Os empreendimentos pesquisados apresentam em média, tempo de existência de aproximadamente 17 anos. A Figura 5 apresenta a série dispersiva do tempo de existência e da quantidade de empreendimentos. 


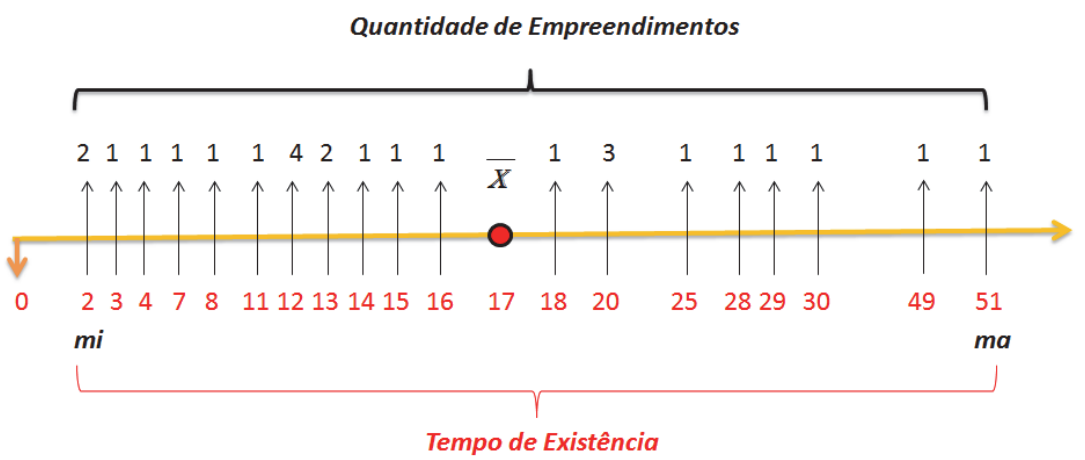

Fig. 5: Série dispersiva de tempo. Fonte: $N G D / L D U$ (2016)

Dos 4 empreendimentos que apresentam 12 anos de existência, 3 são de Blumenau e 1 de Joinville. Dois empreendimentos estão no início do negócio, apresentando 2 anos de duração. Um é filiado a uma associação que conduz os interesses da categoria e o segundo nasceu de necessidades particulares de um dos membros, proprietários do negócio.

O empreendimento com mais tempo de vida localiza-se em Blumenau e atua na área de fruticultura e olericultura. Sua principal atividade é a plantação de cana e a transformação em melado, atividade econômica permanente, considerada a principal fonte de geração de riquezas e não querem o desenvolvimento da atividade turística. Também de forma secundária atuam igualmente na olericultura com raízes e tubérculos sendo a primeira uma atividade sazonal e a segunda permanente. A venda in natura de tubérculos e raízes apresenta uma atividade econômica secundária.

Um (1) empreendimento manifesta preocupação com a questão da sucessão do negócio, visto que os membros mais jovens da família agrícola não querem dar continuidade aos negócios dos pais, preferindo outras atividades não agrícolas e fora do meio rural.

Igualmente, algumas propriedades demandam assessoria na gestão em todos os níveis do empreendimento necessitando de auxílio na formação patrimonial da marca e do negócio, bem como da criação de alianças estratégicas que ampliem e reforcem o design, através de ações coletivas, inovadoras e associadas.

Os empreendimentos traduzem o potencial da produção manual através de um processo histórico e único, conferindo autenticidade ao sistema produtivo mesmo que haja certa reprodutibilidade técnica, posto que o conceito de autenticidade decorra justamente do saber que o produziu e não do bem em si (Sant'anna, 2003).

As práticas desenvolvidas são expressões culturais imateriais herdadas dos seus antepassados e são reproduzidas continuamente através das gerações que a detém, constituindo uma forma de compreensão e vivência da vida social, cultural, econômica, política e cultural dos grupos num misto de tecnologia e arte, sem perder a validade ética e estética (Benjamim, 1992).

Isso amplifica as possibilidades de utilização dessas características para empregar o design na atividade do turismo no espaço rural, já que a harmonia ambiental, a formação étnica de seus membros, o conceito campesino, o partido arquitetônico das construções aliado as atividades produtivas, lúdicas e artesanais, torna o meio rural um ambiente dinâmico o que amplifica consideravelmente a criação de postos de trabalho fomentando a multifuncionalidade do espaço rural, minimizando os efeitos deletérios das ocupações rurais não agrícolas, pela "desdiferenciação social atrelada a pluriatividade" (Laurenti e Del Grossi, 1999, p.17). 
A partir das análises efetuadas, desenvolveu-se uma base taxonômica das atividades dos empreendimentos, como auxílio na organização da informação, estruturada em classe, subclasse, gênero e renque (Figuras 2 e 3) como suporte para navegação, organização e reusabilidade da informação, conforme pode-se observar na Figura 6.

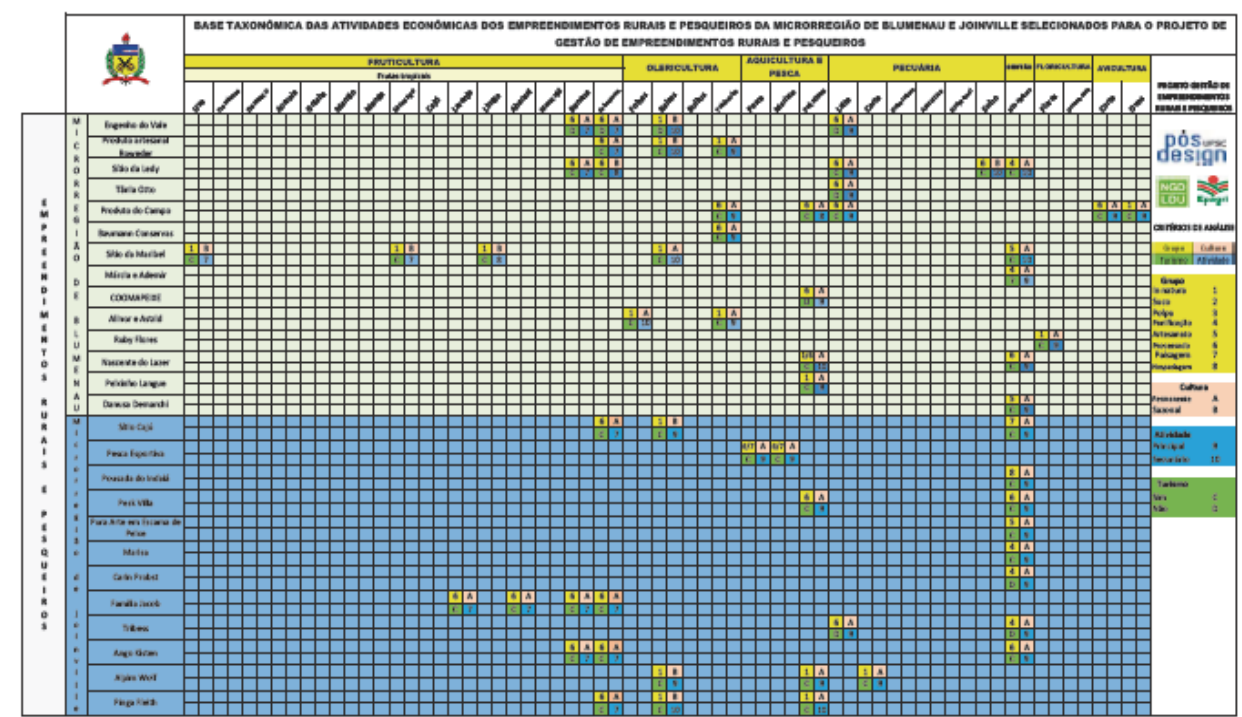

Fig. 6: Base taxonômica das atividades econômicas dos empreendimentos rurais e pesqueiros analisados. Fonte: $N G D / L D U$ (2016).

Assim com base na composição e leitura das propriedades consignadas na subclasse da base taxonômica, apresenta-se o Gráfico 1, A e B.

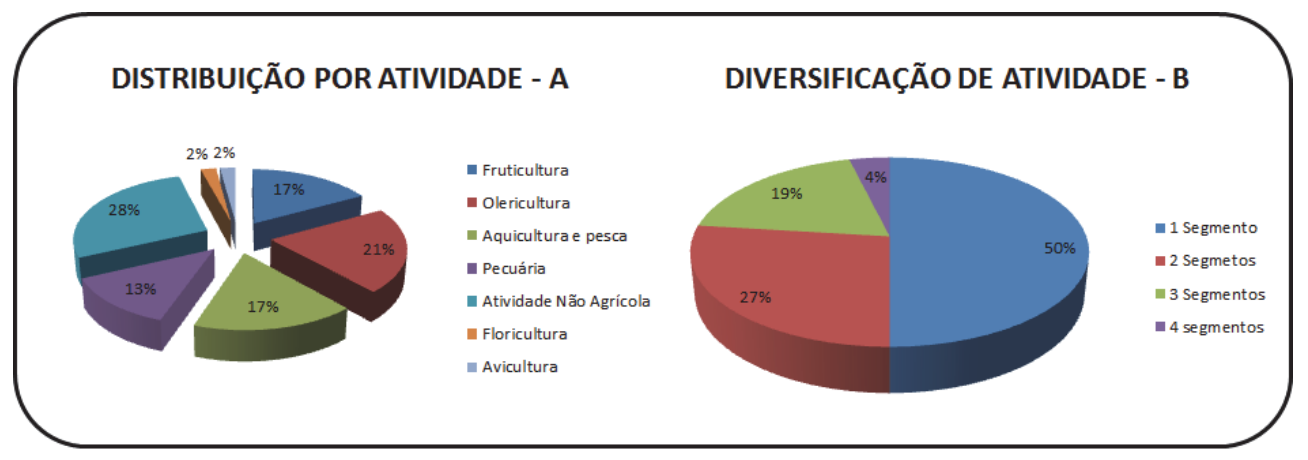

Gráfico 1: Distribuição por atividade e diversificação da oferta. Fonte: NGD/LDU (2016).

É possível inferir-se com a exposição dos dados do Gráfico A, que as atividades convergem para panificação, artesanato, hospedagem, contemplação de aves e paisagem, além de processamento de 
produtos in natura oriundos da psicultura, mas que também não se traduzem como atividade principal, vez que oferecem à produção processada de alimentos. Este estrato alcança $23 \%$ da amostra.

A segunda atividade mais executada nas propriedades é a olericultura, compreendendo um universo de $21 \%$, seguido da fruticultura e aquicultura e pesca com $17 \%$ cada categoria. A quarta atividade mais praticada nos empreendimentos é a pecuária para produção leiteira e derivados (13\%), identificada como atividade permanente. Floricultura e avicultura abarcam, cada categoria, $2 \%$.

A sobreposição do Gráfico B, a partir do conhecimento gerado com o Gráfico A, permite deduzir que no que diz respeito ao conceito de diversificação (Ansoff, 1981), o tema apresenta-se de forma pouco explorada. Somente um (1) empreendimento atua em quatro (4) categorias, nomeadamente olericultura, psicultura, pecuária para produção leiteira e avicultura para corte e produção de ovos, todas elas, segundo declaradas por seus agentes produtivos, como sendo, atividade permanente e assumindo a principal fonte de geração de riquezas do empreendimento.

Constata-se, por meio da navegação da base taxonômica que os empreendimentos rurais localizados na região de Blumenau atuam nas 7 classes da base. Na subclasse é possível verificar a produção de uvas, morango, limão, assim como também banana e cana de açúcar, classificada na subclasse como atividade sucroalcooleira. Exceto esses dois últimos, todos os outros são comercializados in natura, considerados culturas sazonais e que adicionalmente potencializam riquezas para a propriedade. Com relação aos dois últimos, no micro espaço grupo, tanto a banana quanto a cana de açúcar são processados para fabricação de geleias, doces e melado.

A preponderância nas outras classes é mantida no processamento da psicultura (Filés e outros cortes), de lácteos para queijo, natas e iogurtes, panificados e artesanato. Com relação ao desenvolvimento do turismo organizado, duas propriedades não querem adicioná-las na propriedade.

Já as propriedades rurais localizadas em Joinville, concentram suas atividades em 6 classes excetuando avicultura. Na subclasse frutas tropicais atuam produzindo laranja, abacaxi, banana e cana de açúcar. Assumem a condição de produtores permanentes e tem na atividade a principal fonte de geração de riquezas da propriedade.

$\mathrm{Na}$ classe olericultura, subclasse raízes, duas propriedades produzem de forma sazonal, comercializando a colheita do aipim e considerada para um como a fonte de principal riqueza, e para o outro, como sendo uma atividade secundária.

Nas classes pecuária e gestão, há uma variação quanto as subclasses, com alinhamento mimético no gênero, com somente duas propriedades contrárias ao desenvolvimento do turismo. Ainda nessas duas classes, no microespaço grupo, integrante do primeiro renque, (1) propriedade explora a contemplação da paisagem e a observação de pássaros; (1) atua no ramo de hospedagem; (3) com panificação e (1) com artesanato.

Assim, de acordo com a base taxonômica é possível afirmar que é possível a valorização da agricultura familiar, nos casos em tela, pela quantidade de práticas, processos, insumos e equipamentos necessários para a sistemática reprodutibilidade de um sistema usado para transformar entradas em saídas de qualidade. Como um sistema que opera em um layout específico dentro de uma capacidade planejada, reportando a estrutura física aos relacionamentos humanos, a partir de um conjunto de elementos com suprimentos, máquinas e equipamentos, as evidências contribuem para a valorização da agricultura familiar.

Finalmente a convergência das ações desencadeou uma série de respostas aos agricultores e como resultado da prática projetual dessas ações por meio do design, valorizam a agricultura familiar por meio 
da criação de identidades visuais, de embalagens e humanização dos pontos de venda, oferecendo aos consumidores, produtos diferenciados.

Os ativos intangíveis, a partir da evidência da constatação da localização, do material de comunicação, da interpretação dos símbolos através dos signos visuais e logotipos, deixam claro que a valorização a identificação e a proteção, se transformam em ativos intangíveis na agricultura familiar, e isso enriquece o apelo ao consumidor.

No entanto, considera-se como principal ativo resultante dessas ações o fornecimento sinergístico entre o ambiente interno e o externo, mas acima de tudo a evidência física e imaginária, que posiciona o negócio, a marca e o produto como agentes de qualidade.

Portanto foram realizadas melhorarias no ponto de venda para exposição atrativa das mercadorias, com ações de branding/naming, criação de marca gráfica e linguagem visual padronizada, envolvendo questões legais como o registro de marca, nome fantasia e nome empresarial e serviços para melhorar a experiência de compra e a conscientização sobre hábitos saudáveis; criação de tags informativas para os produtos; plaquinhas com nome / preço dos produtos; cartaz institucional do produtor; quadro negro com produtos do dia e cestos de vime para expor os produtos. Já em Joinville, o efeito final foi à identidade visual, nas embalagens, uniformes, papelaria, aplicações de identidade visual nos meios de transporte da cooperativa e estudos ergonômicos para despencamento das pencas de banana.

\section{Considerações finais}

As relações estabelecidas entre a agricultura familiar e a gestão de desing por meio da base taxonômica apontam mesmo que preliminarmente, valorização da agricultura familiar por meio dos ativos intangíveis, uma vez que as 26 propriedades estudadas desenvolvem processos produtivos, com tecnologias apropriadas e conhecimento necessário para a produção rural familiar.

Deve-se registrar que os resultados positivos na perspectiva da produção de ativos intangíveis vistas e discutidas relaciona o conceito como elemento catalisador de benefícios econômicos futuros: para o produtor e para o consumidor. O produtor com a perspectiva da convergência desses ativos em valores absolutos e o consumidor com as diversas possibilidades de satisfação de suas necessidades e desejos, a partir da compreensão e interpretação desses ativos intangíveis.

Considere-se ainda que a produção dos ativos intangíveis tais como valorização, identificação e proteção, aumentam as chances do negócio obter saúde e longevidade, mantendo o agricultor familiar no campo e diminuindo as chances desse agente produtivo sofrer as consequências negativas do abandono da atividade primária.

Alie-se a esse fato que a manutenção de pequenos grupos produtivos no espaço rural diminui a probabilidade da presença e dominância da agroindústria patronal com seu modelo de produção agressivo, comoditizado, produzido em larga escala. Esse modelo de produção aumenta a pressão ambiental e por outro lado dilata ainda mais o remoto rural, não como uma relação geográfica medida em distância, mas sobretudo a possibilidade do espaço rural perder a presença do homem e suas relações tipicamente rurais.

No que concerne à diferenciação, o desenvolvimento de novos produtos mantêm o destaque e constrói uma participação de mercado mais consistente. Contudo o principal papel determinante da diferenciação é o desenvolvimento de novos atributos na curva de valores do negócio. Também a organização e 
humanização dos pontos de venda, incluindo aspectos de layout afeta a capacidade de diferenciação dos produtos.

Nesse viés a autenticidade do processo produtivo e dos insumos de produção resulta na habilidade dos empreendimentos em exercer suas atividades de forma exclusiva, e isso cria valor e influencia a percepção da diferenciação. Dessa forma o projeto gestão de empreendimentos rurais por meio da gestão do design na dimensão da diferenciação, estabelece esforços apresentando os benefícios do consumo da origem familiar da produção agrícola desenvolvendo a agrobiodiversidade.

A dimensão sustentabilidade proporciona que os empreendimentos alicercem seus sistemas de atividades a partir das interconexões mais relevantes do sistema produtivo. Isso elimina custos, diminui riscos e aumenta as dificuldades de imitação dos concorrentes atuais. Esses resultados oriundos de um modelo de planejamento e gestão contribuem para a sustentabilidade, uma vez que desenvolve capacidades e habilidades específicas que reforçam o DNA do negócio, aumentando sua longevidade, manutenção e permanência no negócio. A compreensão dessa nova economia, solidária, social e popular sustenta um estilo de vida, influenciando significativamente nos hábitos alimentares mais saudáveis e na produção alimentar mais sustentável.

Por fim a construção preliminar da base taxonômica teve como objetivo o estabelecimento de uma categorização do que até o momento foi pesquisado, permitindo uma visão e leitura mais clara sobre as semelhanças e diferenças presentes entre as propriedades estudadas.

Assim as verificações apontadas por meio da base taxinômica neste estudo multicaso, pode-se afirmar que o papel da gestão de design aqui discutido vai além do desenvolvimento de embalagens e rotulagem: o papel do design neste viés consiste sempre em oferecer a melhor resposta através de um posicionamento competitivo, com linguagem clara criando compromisso entre os agentes direta e indiretamente envolvidos e isso amplifica o valor dos ativos intangíveis na agricultura familiar.

\section{Referências}

ANSOFF, H. Igor. (1981). Administração estratégica. São Paulo: Atlas.

BRASIL. MINISTÉRIO DO DESENVOLVIMENTO AGRÁRIO. (Org.) (2010). Um novo Brasil rural. Brasília:

\begin{tabular}{|c|}
\hline Ministério \\
\hline
\end{tabular}

$<$ http://www.mda.gov.br/sitemda/sites/sitemda/files/ceazinepdf/4405346.pdf >. [Consulta: 25 de fev. 2016]

BRASIL. MINISTÉRIO DO DESENVOLVIMENTO AGRÁRIO. (Org.) (2016). Dados estatísticos. Brasília: Ministério do Desenvolvimento Agrário. http://www.mda.gov.br/. [Consulta: 25 de fev. 2016.

BRASIL. (1996). Lei n. 9279 de 14 de maio de 1996. Regula direitos e obrigações relativos à propriedade industrial. Brasília, 14 de maio de 1996.

BRASIL. UNIVERSIDADE FEDERAL DE SANTA CATARINA. (2016). Departamento de Expressão Gráfica. Programa de Pós-Design. Núcleo de Gestão de Design. Base taxonômica das atividades econômicas dos empreendimentos rurais e pesqueiros analisados. Florianópolis: UFSC.

BRASIL. UNIVERSIDADE FEDERAL DE SANTA CATARINA. (2016). Departamento de Expressão Gráfica. Programa de Pós-Design. Núcleo de Gestão de Design. Distribuição por atividade e diversificação da oferta. Florianópolis: UFSC.

BRASIL. UNIVERSIDADE FEDERAL DE SANTA CATARINA. (2016). Departamento de Expressão Gráfica. Programa de Pós-Design. Núcleo de Gestão de Design. Resultados do processo criativo de geração de conceito. Florianópolis: UFSC. 
A gestão de design na perspectiva da produção de ativos intangíveis na agricultura familiar: Um estudio multicaso em Joinville e Blumenau no estado de Santa Catarina,

BITENCOURT, G. A. y BIANCHINI, V. (1996). Agricultura familiar na região sul do Brasil. Consultoria UTF/036-FAO/INCRA.

BENJAMIN, W. (1992). A obra de arte na era da sua reprodutibilidade técnica. in Sobre Arte, Técnica, Linguagem e Politica, Antropos, Lisboa, Relógio D’Água Editores. vol. 1, p. 71-113

CASTEIÃO, A L. \& LANDIM, P. C. (2009) Quatro modelos de gestão organizacional comprovando a qualidade por meio do Design. Bauru: Congresso Internacional de Pesquisa em Design - CIPED.

CAMPOS, M. L. de A.,GOMES, H. E. (2007). Taxonomy and classification: the principle of categorization en VIII ENANCIB - Encontro Nacional de pesquisa em ciência da informação. Salvador. Disponible en: $<$ http://www.enancib.ppgci.ufba.br/artigos/GT2--101.pdf> [Consulta: 31 maio 2016]

EPAGRI/CEPA. (2016). Secretaria de Estado de Educação e da Pesca. Santa Catarina e as microrregiões de Blumenau e Joinville. Florianópolis. Epagri/Cepa, 2016. http://www.epagri.sc.gov.br/?page_id=3210. [Consulta: 14 de mar. 2016]

GIL, A.C. (2001). Como elaborar projetos de pesquisa. São Paulo: Atlas.

GORB, P. (1990). Design Management. New York: Van Nostran.

GOULART, M. C. F., MERINO, E. A. D. y MERINO, G. S. A. D. (2013). Gestão de design na maricultura como fator estratégico para a competitividade. Strategic Design Research Journal. Porto Alegre, v. 3, n. 6, p.116-126, jul. 2013: <http://revistas.unisinos.br/index.php/sdrj/article/view/sdrj.2013.63.04/4241>. [Consulta; 09 de mar. 2016]

GARCIA, E. A. da R. (2001). Ativo intangível: goodwill e capital intelectual, uma necessidade de evidenciação nos relatórios contábeis en: VII CONGRESSO DEL INSTITUTO INTERNACIONAL DE COSTOS E II CONGRESSO DE LA ASSOCIACÍON ESPAÑOLA DE CONTABILIDAD DIRECTIVA. Disponible en: $<$ http://www.intercostos.org/documentos/Trabajo067.pdf $>$. [Consulta: 20 de maio 2016]

LAKATOS, E.M. y MARCONI, M. de A. (2003). Fundamentos da metodologia científica. São Paulo: Atlas.

LAURENTI, A. C.., DEL GROSSI, M. E. (2000) A evolução das pessoas ocupadas nas atividades agrícolas e nãoagrícolas nas áreas rurais do Brasil. In: Campanhola, C.; Graziano da Silva, J.. (Org.). O Novo rural Brasileiro: uma análise nacional e regional. Jaguariúna: EMBRAPA.

MERINO, E. A. D. et al. (2012). Valorização do produto de grupos produtivos de pequeno porte a partir de uma nova embalagem: o caso de uma embalagem de farinha de mandioca. Extensio, [?], v. 9, n. 14, p. 55-65. $<$ https://periodicos.ufsc.br/index.php/extensio/article/view/1807-0221.2012v9n14p55>. [Consulta: 23 de maio 2016]

MATTEI, L. (2014). O papel e a importância da agricultura familiar no desenvolvimento rural contemporâneo. Rev.

Econ. Ne. Fortaleza, v. $\quad$ N5, $\quad$ n. $45, \quad$ p.71-79, $<$ http://www.bnb.gov.br/documents/80223/205365/ren_2014_6_lauro_v2.pdf/72b45117-194f-4a4b-8b1d-

58b1f893af40>. [Consulta: 23 maio 2016]

TEIRA ARNOSO, A. (2013). Adecuación y validación de una cámara reverberante a escala para ensayos de pantallas acústicas. Trabajo Final de Máster. Valencia: Universitat Politècnica de València, <http://riunet.upv.es/handle/10251/29015> [Consulta: 15 de junio 2013]

NIEDERLE, P. A. (2011). Compromissos para a qualidade: projetos de indicação geográfica para vinhos no Brasil e na França. Trabajo Final de doctorado. Rio de Janeiro: Universidade Federal Rural de Rio de Janeiro.

NETO, A. (2011). A gestão de design e o direito de propriedade industrial Brasileiro: uma abordagem para identificação e proteção de grupos produtivos atrelados à origem por meio de marca e indicação geográfica. Trabajo Final de Máster. Florianópolis: Universidade Federal de Santa Catarina

NETO, A., TEIXEIRA, J. y MERINO, E. A. D. (2010) A contribuição da gestão do design na valorização de grupos produtivos de pequeno porte vinculados a origem. Ingepro: inovação, gestão e produção, [?], v. 2, n. 5, p. 96103.<http://www.ingepro.com.br/Publ_2010/Mai/246-649-1-PB.pdf>. [Consulta: 24 de maio 2016]

PORTUGUEZ, A. P. (2001). Consumo e espaço: turismo, lazer e outros temas. São Paulo: Roca. 
PÁDUA, J. A. (2002). Um sopro de destruição: pensamento político e crítica ambiental no Brasil escravista (17861888). Rio de Janeiro: Zahar.

PRETO, S. C. S., MERINO, E. A. D. y FIGUEIREDO, L. F. G. (2011). Gestão estratégica de Design e Aprendizagem Situada em comunidades tradicionais locais. Projetica: Revista cientifica de design, v. 1, n. 2, p.5-14, jun. 2011. <http://www.uel.br/revistas/uel/index.php/projetica/article/download/9564/9237>. [Consulta: 14 mar. 2016]

RICHARDSON, R. J. (1989). Pesquisa social: métodos e técnicas. São Paulo: Atlas.

RISTOW, D. T. (2015). Gestão de design aplicada à valorização da agricultura familiar. Proyecto Final de Curso. Florianópolis: Universidade Federal de Santa Catarina.

SANT'ANNA, M. A. (2003). Face imaterial do patrimônio cultural: os novos instrumentos de reconhecimento e valorização, En Lastra Abreu, R., Chagas, M. (Org.). Memória e patrimônio: ensaios contemporâneos. Rio de Janeiro: DP\&A.

TEIXEIRA, J. M. (2011). Identificação e proteção: o design valorizando grupos produtivos de pequeno porte. Trabajo Final de Máster. Florianópolis: Universidade Federal de Santa Catarina 